\title{
Family physicians' problems with patients and own limitations - a qualitative study
}

\author{
JUSTYNA BANKIEWICZ-NAKIELSKA ${ }^{1,4-F}$, MACIEJ WALKIEWICZ ${ }^{2, \text { D-F, }}$ \\ ORCID ID: 0000-0003-1141-2441

MONIKA TYSZKIEWICZ-BANDUR ${ }^{1, D, F}$

ORCID ID: 0000-0001-7505-8061

${ }^{1}$ Centre of Psychoanalytic Therapy Continuum, Szczecin, Poland

${ }^{2}$ Faculty of Psychology, Medical University of Gdańsk, Gdańsk, Poland

A - Study Design, B - Data Collection, C - Statistical Analysis, D - Data Interpretation, E - Manuscript Preparation, F - Literature Search, G - Funds Collection

Summary Background. Family physicians cooperate in the treatment process, not only with patients, but also with other medical professionals. There is no doubt that their psychological competency, such as communication skills and emotional intelligence, are just as important as their clinical experience.

Objectives. The aim of the present study was to identify the difficulties that family physicians encountered in working with patients, as well as with their work-related emotions.

Material and methods. A total of 36 physicians in the final year of specialisation in family medicine were engaged in the research. Results. Family physicians reveal that dealing with aggressive patients, setting boundaries with patients and motivating them to treatment were the hardest for them in their work. There are specific psychological difficulties experienced by family physicians (e.g. helplessness of self-limitation, disharmony between experienced feelings and beliefs about the duty of a doctor, contradictory attitudes towards patient autonomy). The way to prepare for the professional role of a physician leads to the reinforcement of strict injunctions and prohibitions on the performance. Consequently, this leads to the development of ineffective strategies to build relationships with the patients and also deal with physicians' own emotions.

Conclusions. The present study may be helpful for the development of a set of psychological tools useful for solving problems raised by the family physicians in the intra- and interpersonal area and during specialisation training.

Key words: compliance, medical education, family physician, communication.

Bankiewicz-Nakielska J, Walkiewicz M, Tyszkiewicz-Bandur M. Family physicians' problems with patients and own limitations - a qualitative study. Fam Med Prim Care Rev 2020; 22(1): 18-21, doi: https://doi.org/10.5114/fmpcr.2019.90173.

\section{Background}

In medicine, the effects of treatment are conceptualised as specific or non-specific. Specific are concrete components, such as medication or surgery. Research data suggest that non-specific effects explain a considerable amount of the variation in patient outcomes in clinical trials. Non-specific effects account for almost $60 \%$ of the variance in outcomes across clinical trials [1], indicating that non-specific treatment effects would be more important than specific effects [2] and that the effectiveness of medical procedures also depends on the quality of the physician-patient relationship [3]. Essential elements of the physician-patient relationship include verbal and non-verbal communication, effective questioning and transmission of information, expression of empathy and concern, partnership and participatory decision-making $[4,5]$. More effective physician-patient communication is linked empirically to the outcomes of care, including patient satisfaction, health status, recall of information, adherence and less patient litigation [6-8].

Adherence (synonymous with compliance) describes the degree to which a patient correctly follows medical advice. Most commonly, it refers to medication or drug compliance but can also apply to medical device use, self-care, self-directed exercises or therapy sessions. Both the patient and healthcare provider affect compliance, and a positive physician-patient relationship is the most important factor in improving adherence
[9]. A meta-analysis found that the odds of having adherent patients were twice as high if physicians were good communicators [10].

Family physicians cooperate in the treatment process, not only with patients but also with other medical professionals. There is no doubt that their psychological competency, such as communication skills and emotional intelligence, are just as important as their clinical experience [11]. For example, evidence shows that family physicians with a higher psychological competency have fewer court cases [8].

Millions of visits that resulted in patient non-adherence would have resulted in better patient adherence if the physician possessed strong interpersonal communication skills. These estimates are only suggestive, but they highlight the potential importance of communication in reducing wasted healthcare resources that result from non-adherence [12]. Healthcare providers play a great role in improving adherence issues and can improve patient interactions through motivational interviewing and active listening [13].

A model of practicing medicine defined as "Relationshipcentred Care" (RCC) has been proposed. This model is based on the assumption that "all illness, care and healing processes occur in relationships of an individual with themselves and with others. (...) RCC can be defined as care in which all participants appreciate the importance of their relationships with one another and is founded upon four principles: 1) relationships in 
healthcare should include the personhood of the participants; 2) effect and emotion are important components of these relationships; 3 ) all healthcare relationships occur in the context of reciprocal influence; and 4) the formation and maintenance of genuine relationships in healthcare is morally valuable. In RCC, relationships between patients and clinicians remain central, although the relationships of clinicians with themselves, each other and the community are also emphasised" [14]. Training in communication is an essential and effective component of medical education and may be even more important in residency training for physicians [15].

\section{Objectives}

The aim of the present study was to identify the difficulties that family physicians encountered in working with patients, as well as with their work-related emotions.

\section{Material and methods}

\section{Participants}

A total of 36 physicians in the final year of specialisation in family medicine were engaged in the research when they took part in a postgraduate course regarding communication with patients, which was organised at a medical university $(75 \%$ female).

\section{Study design and data collection}

The data was collected using a qualitative method. The choice of such methodology was based on the assumption that in-depth analysis of a smaller number of cases rather than more superficial ones is better suited to the study $[16,17]$. In the case of the importance of psychological competence in a physician's work, it appears more important to understand the reality of the physician's point of view more thoroughly than to use existing theoretical models. The semi-free interview method was based on respondents' free answers related to their experiences, facts and memories. The task of the researcher was to determine the area of interest and the main topic of conversation. Mainly open questions were set out before the interview; however, there was no need to adhere to the order in which they were asked. This method is particularly useful in research where the problem concerns deeply personal and difficult matters, as well as those with subtle meanings that are not fully understood. An audio recording was obtained. The method allows for in-depth knowledge of the problem being examined and enables gathering many types of information, which reaches specific and deeper content, e.g. shame, fear, sadness, etc. It allows for analysis of all content appearing during the interview (both verbal and non-verbal) and contextual information.

\section{Data analysis}

The procedure for analysis of the interviews (audio material) was to study the recordings of the statements and the transcription, followed by selection of the problem categories that appeared in the opinion of the physicians. The group of competent judges consisted of three psychologists with professional experience in the range of 5-15 years, trained in the field of quality analysis and interpretation of data. Subsequently, the material prepared by the competent judges revealed the problem categories that appeared the most often in the judges' opinion and the psychological tools needed to solve them. In the next step, the respondents' statements were subjected to interpretative phenomenological analysis (IPA) [18, 19]. IPA is an approach to psychological qualitative research with an idiographic focus, which means that it aims to offer insight into how a given per- son, in a given context, makes sense of a given phenomenon. Usually, these phenomena relate to experiences of some personal significance, such as a major life event or the development of an important relationship. IPA is one of several approaches to qualitative phenomenological psychology. It is distinct from other approaches, in part due to its combination of psychological, interpretative and idiographic components [20,21].

The competent judges first read and listened to the testimonies repeatedly, making notes on their own observations and reflections on the subject of the interview. They took into consideration the semantic, linguistic (metaphors, symbols, repetitions, pauses) and contextual (characteristics of the interviewer, age, gender, etc.) content. The judges also analysed the emotional reactions. Subsequently, they distinguished the emerging themes (categories, motives) and associated them with the psychological way of understanding.

In the next stage, relationships between the identified themes were evaluated and grouped according to similarity, and the collected topics were re-examined and re-referenced to the source text, allowing for a review in a broader context. Finally, the topics were interpreted in relation to selected psychological theories. In the last step, an analysis and preparation of material from the competent judges were performed. Topics, motives and semantic units typically appearing in their assessments were selected and subjected to psychological interpretation.

\section{Ethical consideration}

The study was authorised by the Bioethics Committee of the Pomeranian Medical University in Szczecin, Poland (KB0012/95/10/13).

\section{Results}

Based on the analysis of the material prepared by the competent judges, problem categories appearing most often in the respondents' statements were classified.

\section{Aggression}

Aggression and frustration of the patient. Aggressive behaviour of parents of child patients. Attacks on the physician by the patient's family and escalation of anger. Interruption of the visit by another patient. Non-acceptance by the patient of the physician's refusal. Expression of anger and frustration by expectant patients regarding waiting. Questioning by the patient of the physician's recommendations. Expectation by the patient that the physician explains their actions. Crossing of the barrier by the patient. Anger of the family of deceased patients. Expectation by the patient that the physician constantly be ready to work. Forcing referrals and other benefits.

\section{No authority}

Questioning by the patient of the physician's recommendations. Expectation by the patient that the physician explain their actions. Problems in relation to personnel (informing patients of conflicting information, switching phones, among others). Fear of losing patients.

\section{Lack of recognition of the patient's autonomy}

Helplessness in the face of decisions made by the patient. Lack of physician's acceptance of the patient's choice. Taking responsibility for patient decisions. Advising the patient. Excessive involvement in patients' affairs. Patient's discomfort. Questioning by the patient of the physician's recommendations. Allegations of the subject treatment of patients. Concealing information about the patient's condition. Consultation by the patient with another doctor. Self-diagnosis based on information from 
the Internet (in the opinion of the respondents: "competing" with the physician's knowledge). Refusal by the patient to report suspicions of committing a crime.

\section{Dissonance between feelings and beliefs}

Dissonance between anger at the patient and the conviction that the physician should be caring and kind (conflict between emotions and an internalised recipe for their professional role). Blocking anger towards the patient. Internal conflict related to reporting a suspicion that a patient or his family have committed a crime. Ambivalence - sympathising with the patient and at the same time being angry with them. Internal disagreement of aggressive behaviour by the patient's family and verbal attacks towards the physician and at the same time reluctance to put up a barrier (perception of possible solutions to the situation: escape or "raising the voice" - no tools to set limits "between aggression and submission").

\section{Physician's emotions}

Helplessness of the physician to the patient's decisions. Anger towards patients. Anger towards medical personnel (related to crossing physician's boundaries). Anger towards the patient for chasing them and not respecting other patients. Aggressive boundary setting by the physician. Discomfort and anxiety when in close contact with the patient. Afraid of the patient. Ambivalence - physician feels sorry for the patient but at the same time is angry with them. Anger towards the patient because they "take up time" telling them about their experiences. The anger of other physicians working in the team. Anger towards the patient for coming to the physician with small details during work, even when they are ill. Fear of being perceived as aggressive.

\section{Psychological games}

Patient crying in response to information that the physician has suspicions of them committing a crime (emotional blackmail, psychological involvement). Feeling of being used. Asking female patients questions to determine their husbands' abuse. Conflicting information being provided to patients by medical personnel (other than information from another physician). Psychological "secrecy games" - sharing a secret with the patient's family. Excessive involvement in patients' affairs. Difficulties associated with being endowed by patients.

\section{Uncertainty, worry, guilt}

Physician "brings work home", "chews over the situation". Physician is unsure about their decisions, doubts their actions. Inability to "cut themselves off from the situation". Fear for the health and life of a patient who has not appeared in the office for a long time. Fear of accusations from relatives if "something happened to the patient". Thinking about other ways of responding. "Excessive" taking over. Constant fear for the health of the patient.

\section{Working with a psychologically disturbed patient}

Working with a narcissistic patient. Working with a psychiatric patient or after using psychoactive substances. Working with a patient with personality disorders.

\section{Beliefs about the role of the physician}

Excessive involvement in patients' affairs. Helplessness of the physician and resulting frustration. Negative reaction of medical staff and patients to a physician's assertiveness. Fear of disappointing patient's expectations. Feeling of guilt related to failure to meet patients' needs. Unrealised desire to suggest that the patient change physicians (the patient shows a lot of sympathy - the physician wants to be nice). Anger towards the patient for coming to the physician with small details during work, even when they are ill.

\section{Physician-patient relationship}

Direct questions about the patient's own death. What to do to make the patient feel that they have been cared for although there are no serious medical problems. Discomfort in transmitting difficult messages to the patient. Communication with the patient involving "intermediaries" (sick family). Physician does not want to be involved in the intimacy of the patient. Physician does not feel competent in the context of including them in the emotions of the patient. Physician is angry towards the patient that they "take time" telling them about their experiences. A recurrent psychosomatic patient. Patient explaining about family history not related to the purpose of the medical visit. Patient prolonging the visit. Patient coming to talk about "what's going on with them". Patient confiding in the physician, talking about situations that go beyond the purpose of the visit. Patient calling and apologising that they took up the physicians' time. Patient crying and confiding in the physician. Patient crying due to the refusal to accept a gift. Patient bringing gifts to the physician.

\section{Compliance}

Questioning of the patient about the physician's recommendations. Lack of motivation of the patient to take medication and participate in the therapy recommended by the physician. Reluctance of the patient for specialist consultations. Patient's discomfort. Consultation of another physician by the patient. Self-diagnosis of the patient based on information from the internet ("competing" with the physician's knowledge).

\section{Physician's submission}

Fear of being perceived as aggressive. "Giving up" and succumbing to pressure from patients (regarding, among others, referrals). "Making a good face for a bad game" (including smiling and waiting for the patient to leave the office). Not wanting to offend the patient and be "unpleasant". Pressure from the patient to unjustifiably jump the queue. Family pressure for the physician to arrive quickly. Crossing boundaries by the patient. Inability to set boundaries. Waiting by the patient for the physician's absolute availability. Refusal to write prescriptions for medicines that the patient is waiting for. Feeling of being "paralysed" during every subsequent contact with the patient (psychological position of the victim). Feeling of being used. Desire to suggest that the patient change physicians while the patient shows them a lot of sympathy. Switching phones. Interruption of the physician by the patient. Loss of control over the situation. Telephone consultations of cases requiring a physician's appointment. Participation of third parties during the visit. Anger towards medical personnel for crossing the physician's boundaries. Self-anger resulting from not taking care of themselves in the situation of their own illness. Anger of the physician towards the patient for chasing them and not respecting other patients. Communication with the patient involving "intermediaries" (sick family). Transmission of conflicting information by medical personnel (including information from another physician). Anger towards the patient for coming to the physician with small details during work, even when they are ill.

\section{Knowledge about procedures}

Ignorance about the procedure for dealing with suspected psychological abuse of children by parents.

\section{Discussion}

Analysis of the narratives of the examined family physicians shows the motives that most frequently appear in the state- 
ments about their contact with patients that lead to frustration and powerlessness, which are helplessness against patients' aggression and lack of recognition of the physician's authority. They reported a strong dissonance between the feelings experienced when in contact with the patient and their beliefs about "what is allowed and what is not allowed by the physicians", which resulted from the definition of a professional role. They described difficult emotions such as anxiety, being afraid of closeness with patients and anger towards patients. The motive of patient autonomy and contradictory attitudes was also significant. Other topics that aroused strong emotions in the family physicians included: providing patients with difficult information; experiences of death and conversations about it; showing that they care about patients; reactions to strong emotions of patients; compliance with medical recommendations. In addition, there were motives in their statements connected with worrying about the correctness of their own behaviour and the health of the patient, as well as guilt. The topic of "psychological games" emerging in relationships with patients and personnel to relieve tension and frustration was also identified. The respondents also emphasised difficulties in working with a mentally disturbed patient. In particular, the information submitted by the respondents frequently described the motive of the family physician's compliance and the related action against them- selves, difficulties in refusing patients, internal "compulsion" to satisfy their needs and fear of disappointing expectations.

\section{Limitations of the study}

Firstly, the data was collected through a self-report and may be subject to a social desirability bias. Secondly, the study was conducted in a Pomeranian group of family physicians, thus limiting the transferability of the findings to the general population of family physicians.

\section{Conclusions}

1. Family physicians consider dealing with an aggressive patient, setting boundaries and motivating for treatment the hardest part of their work.

2. There are specific psychological difficulties that physicians experience in their work (including helplessness towards their own limitations, dissonance between experienced feelings and beliefs about the physician's duties, as well as conflicting attitudes towards the autonomy of patients).

3. The present study may be helpful for the development of a set of psychological tools useful for solving problems raised by the respondents in the intra- and interpersonal area and during specialisation training.

Source of funding: This work was funded from the authors' own resources. Conflicts of interest: The authors declare no conflicts of interest.

\section{References}

1. Walach H, Sadaghiani C, Dehm C, et al. The therapeutic effect of clinical trials: understanding placebo response rates in clinical trials - a secondary analysis. BMC Med Res Methodol 2005; 5(1): 26, doi: 10.1186/1471-2288-5-26.

2. Holtedahl R, Brox JI, Tjomsland O. Placebo effects in trials evaluating 12 selected minimally invasive interventions: a systematic review and meta-analysis. BMJ Open 2015; 5(1): e007331.

3. McCabe R, Healey PGT. Miscommunication in doctor-patient communication. Top Cogn Sci 2018; 10(2): 409-424.

4. Roter DL, Frankel RM, Hall JA, et al. The expression of emotion through nonverbal behavior in medical visits. Mechanisms and outcomes. J Gen Intern Med 2006; 21(S1): S28-S34, doi: 10.1111/j.1525-1497.2006.00306.x.

5. Roter DL, Stewart M, Putnam SM, et al. Communication patterns of primary care physicians. JAMA 1997; 277(4): 350-356.

6. Stewart MA. Effective physician-patient communication and health outcomes: a review. CMAJ 1995; 152(9): 1423-1433.

7. Ong LML, de Haes JCJM, Hoos AM, et al. Doctor-patient communication: a review of the literature. Soc Sci Med 1995; 40(7): 903-918.

8. Levinson W, Roter DL, Mullooly JP, et al. Physician-patient communication. The relationship with malpractice claims among primary care physicians and surgeons. JAMA 1997; 277(7): 553-559.

9. De Geest S, Sabaté E. Adherence to long-term therapies: evidence for action. Eur J Cardiovasc Nurs 2003; 2(4): 323-323.

10. Zolnierek KBH, Dimatteo MR. Physician communication and patient adherence to treatment: a meta-analysis. Med Care 2009; 47(8): 826-834.

11. Doyle C, Lennox L, Bell D. A systematic review of evidence on the links between patient experience and clinical safety and effectiveness. BMJ Open 2013; 3: 1570, doi: 10.1136/bmjopen-2012-001570.

12. Kravitz RL, Melnikow J. Medical adherence research: time for a change in direction? Med Care 2004; 42(3): 197-199.

13. Stefanacci RG, Guerin S. Why medication adherence matters to patients, payers, providers. Manag Care 2013; 22(1): 37-39.

14. Beach MC, Inui T, Frankel R, et al. Relationship-centered care: a constructive reframing. J Gen Intern Med 2006; 21(1): S3-S8.

15. Rao JK, Anderson LA, Inui TS, et al. Communication interventions make a difference in conversations between physicians and patients a systematic review of the evidence. Med Care 2007; 45(4): 340-349.

16. Shaughnessy J, Zechmeister E, Zechmeister J. Research methods in psychology. McGraw-Hill Humanities Social; 2014.

17. Flick U. Designing qualitative research. Sage Publications; 2008.

18. Smith JA, Flowers P, Larkin M. Interpretative phenomenological analysis: theory, method, and research. Sage Publications; 2009.

19. Smith JA. Evaluating the contribution of interpretative phenomenological analysis. Health Psychol Rev 2011; 5(1): 9-27.

20. Smith JA. Hermeneutics, human sciences and health: linking theory and practice. Int J Qual Stud Health Well-being 2007; 2(1): 3-11.

21. Gill MJ. The Possibilities of phenomenology for organizational research. Organ Res Methods 2014; 17(2): 118-137.

Tables: 0

Figures: 0

References: 21

Received: 17.05 .2019

Reviewed: 7.06.2019

Accepted: 18.08.2019
Address for correspondence:

Maciej Walkiewicz, PhD

Katedra Psychologii GUMed

ul. Tuwima 15

80-210 Gdańsk

Polska

Tel.: +48 58 349-15-55

E-mail: maciej.walkiewicz@gumed.edu.pl 